\title{
Californians must learn from the past and work together to meet the forest and fire challenges of the next century
}

Susan Kocher, Forestry/Natural Resources Advisor, UC Cooperative Extension Central Sierra

\author{
n 1920, forester Charles Ogle issued a warning about \\ the emerging consensus that all wildfires in forests \\ should be suppressed. "Under natural fire conditions," \\ Ogle wrote in the July 1920 issue of The Timberman, \\ "a proper amount of thinning was effected and the \\ remaining trees were thereby given a better chance \\ to mature." He predicted that trying to extinguish \\ all wildfires would crowd the woods with small trees \\ and leave forests prone to major fires and disease and \\ warned that "a complete destruction of our standing \\ timber of today and the elimination of possible second \\ growth of practical value may be the result" (Ogle 1920).
}

Ogle and other prescribed-fire advocates lost the argument. Today their concerns seem prescient. After a century of fire suppression, California forests are denser and have fewer large trees. Severe fires are increasing in frequency and size throughout the Sierra Nevada. And regeneration is not a given for severely burned forests where seed trees have been killed across large areas.

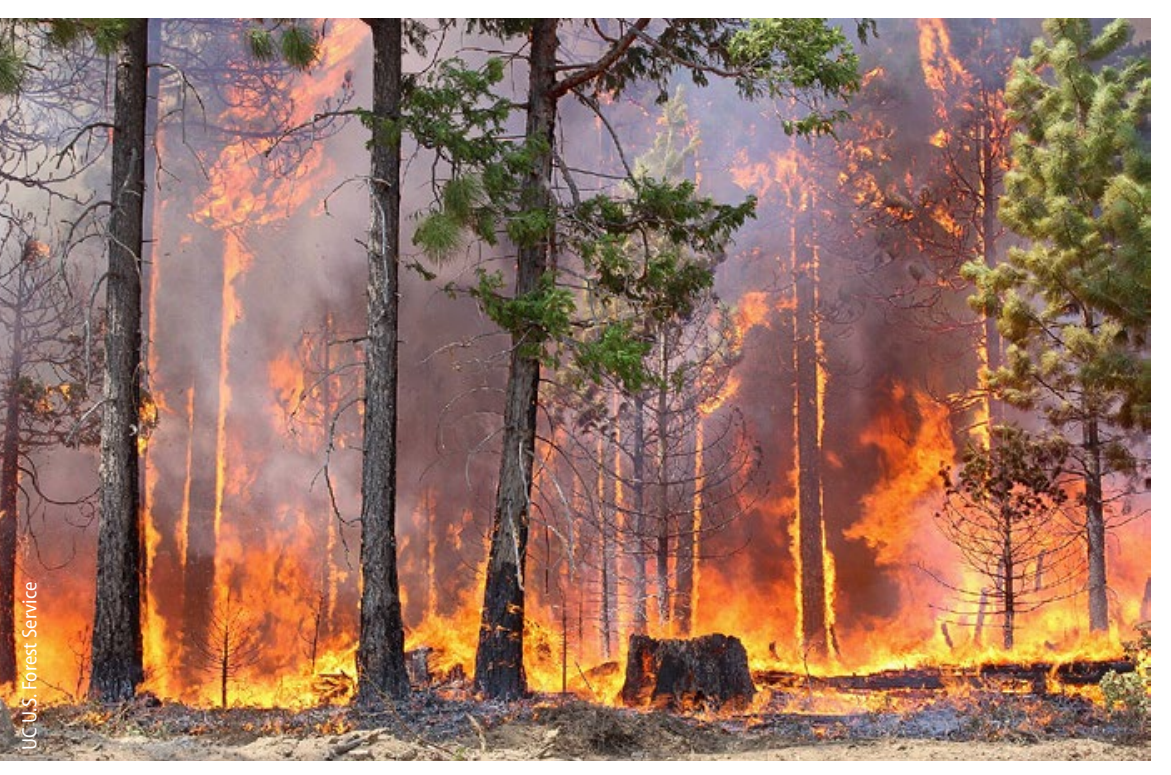

\section{The fire-suppression stalemate}

How have we gotten to this moment of crisis? Though land managers have understood for more than 40 years that fire has an important role in a functioning forest ecosystem, the use of fire to manage forests has remained limited. Fire suppression has led to dramatic increases in forest fuels, and letting wildfires burn now for ecological benefits and hazard reduction is considered too risky in most forests and weather conditions. Thinning forests of small trees and brush can reduce the severity of fires that burn there; however, paying for the work required to get those materials out of the forest is increasingly difficult as the number of mills and biomass-burning facilities has waned in the last decade. Additionally, biological, legal, operational and administrative constraints significantly limit where thinning can be carried out in the 10 national forests in the Sierra Nevada (North et al. 2015).

Decades of successful fire suppression lulled regulators of residential and commercial development into permitting new construction without regard to fire risk. These developments now reduce our ability to use fire to lessen future fire hazard. Attempts to get out of this predicament are made more challenging by political polarization over public land management, the uncertainties of a warming climate and concerns about the impacts of forest thinning on wildlife and the public health effects of smoke from prescribed fires.

Moving toward a healthier role for fire in California forests will be difficult. One area where there is opportunity, however, is in post-fire landscapes. Because today's wildfires tend to be so large and destructive, post-fire areas provide a large landscape on which to try to design a forest that will incorporate wildfire concerns from the beginning. Reforestation can be developed to incorporate fire and warming climate concerns. Restoration sites can also serve as an ongoing laboratory for experimentation, so that forest managers

The Rim Fire began in the Stanislaus National Forest on Aug. 17, 2013 and burned 257,314 acres. More than 100,000 acres burned at high severity, meaning nearly all trees were killed. 
Before fire suppression, roughly $5 \%$ to $10 \%$ of acres burned in wildfires burned at the "high severity" level, intense enough to kill most mature trees. By contrast, $40 \%$ or more of the acreage in recent major fires - such as the 2013 Rim Fire in the Yosemite National Park area and the 2014 King Fire in El Dorado County - has burned that severely.

Fire suppression also affects forest species composition. In the Sierra Nevada, it favors trees that can survive in low light conditions on the forest floor, such as white fir and incense cedar, over those that thrive in open sunny conditions such as ponderosa and sugar pines. Unfortunately, the greatly increased numbers of firs are less likely than pines to survive fire and drought. As a result, many Sierra Nevada forests are much less resilient to water stress and fires, which are exacerbated by a warmer climate.

Foresters 100 years ago also could not have anticipated the cultural and policy shifts that resulted in not harvesting all the trees they so carefully protected from fires. Gone is the social consensus that harvesting timber from forests is a necessary building block of the economy. For decades, public opinion has generally favored policies that support the non-timber values that forests provide, such as recreation, wildlife habitat, spiritual refuges, scenic beauty and the preservation of natural, wild spaces.

\section{The next 100 years}

Emerging issues are continuing to change what California wants from its forests. The role of forests in California's water supply system, for instance, is gaining increasing attention. The Sierra Nevada receives around $30 \%$ of the state's annual precipitation as rain or snow but provides almost $60 \%$ of the state's

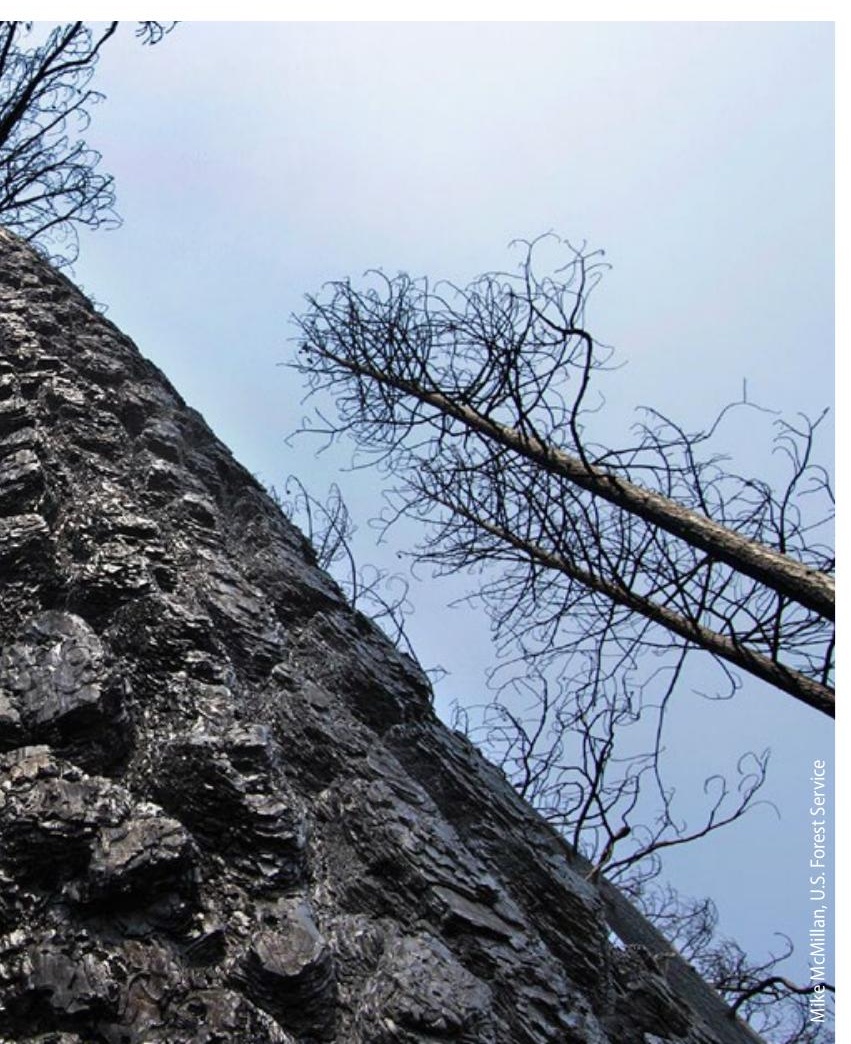

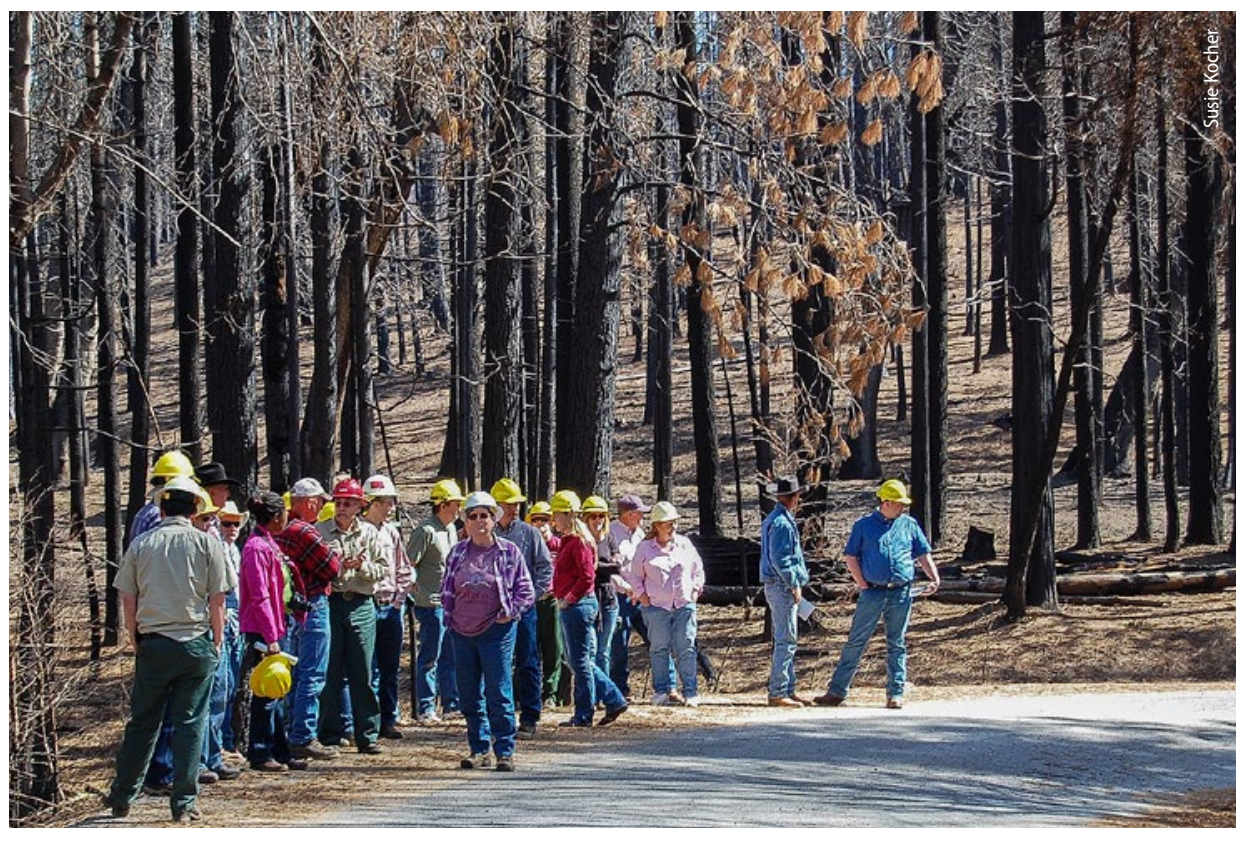

Tour of Rim fire area

water needs. Sierra Nevada forests historically have stored about 15 million acre-feet of water as snowpack each winter. Fire suppression has impaired these water storage and supply functions by increasing the amount of water used by vegetation in overcrowded forests, thus decreasing the amount of water that flows from them. Severe fires also leave the forest floor bare and vulnerable to soil erosion, which often results in degraded water quality. In this season of drought, Californians need resilient forests to provide a reliable water supply.

Climate change is also rapidly changing how fires burn. Average temperatures in California are projected to exceed pre-industrial levels by $3^{\circ} \mathrm{F}$ to $10^{\circ} \mathrm{F}$ by the end of the century, shrinking the annual Sierra Nevada snowpack as much as $90 \%$. Warmer temperatures and a smaller snowpack mean forests will become dry sooner, fire seasons will last longer and accidental ignitions during (the more numerous) dry, windy days will be more likely to cause severe wildfires.

\section{Restoration: An experimental approach}

To address the current crisis, forest managers, researchers, policymakers and the public must work together to increase the resilience of our forests to climate change and wildfire. We must do this even though we, just like the foresters from the turn of the last century, cannot predict the social and ecological conditions in the next century with any certainty.

On public land, increasing the pace and scale of forest fuel reduction treatments is critical, as is more use of prescribed and managed fire. in the Stanislaus National Forest, March 2014. Participants are looking at high severity fire effects where all trees were killed. 


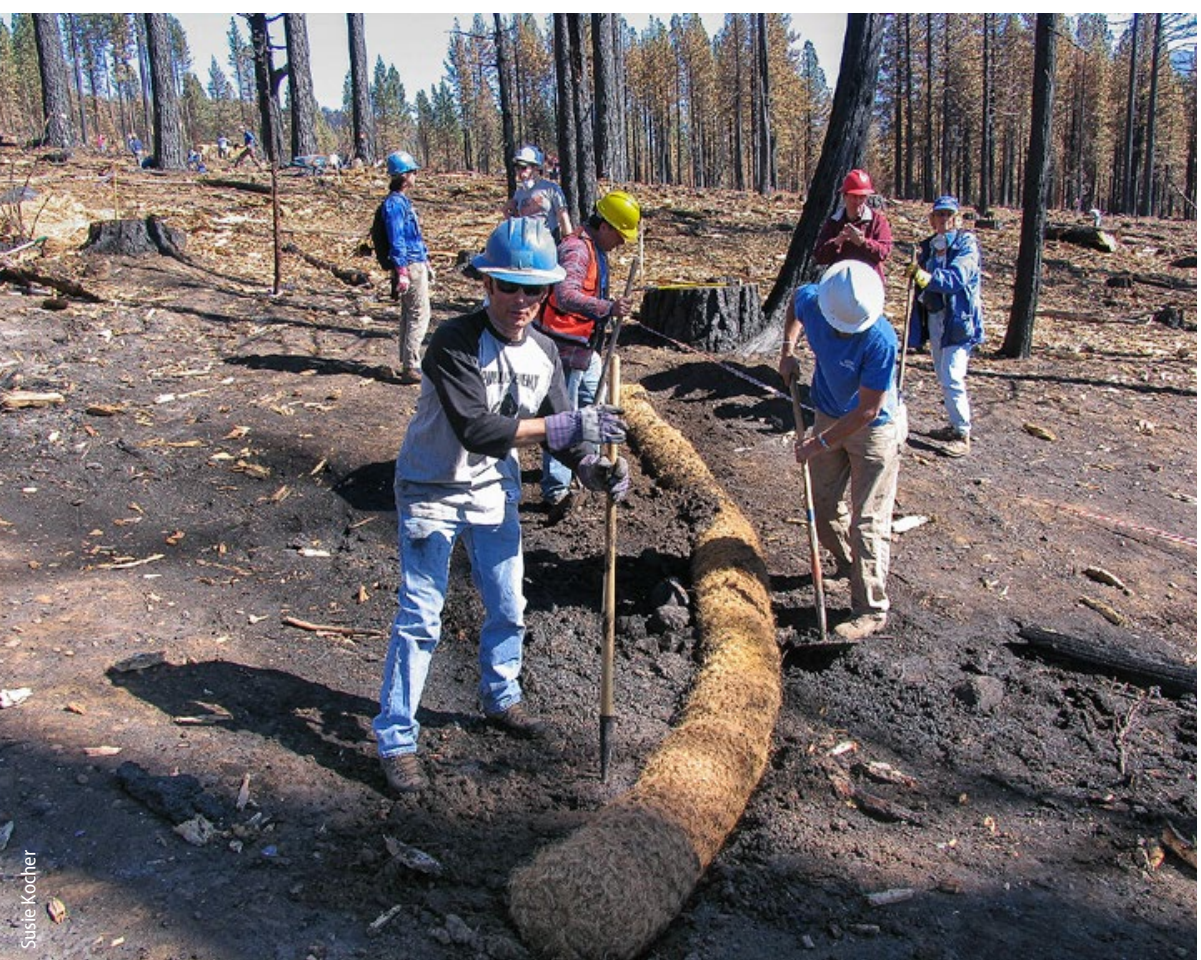

Volunteers for the League to Save Lake Tahoe install erosion control measures following the 2007 Angora fire near South Lake Tahoe. The fire burned 3,100 acres, destroying 250 residences.
On private land, changes in the California Forest Practices Act, which sets tree harvesting and replanting requirements, may be needed to allow the planting of seedlings from areas more suited to the coming climate and to reduce the density of plantations that lead them to be at high risk for fire. Reducing fuels - by thinning, mastication or prescribed fire - is typically expensive, so owners of small forest tracts, which typically do not produce income, need technical and financial assistance in identifying and addressing their climate risks through forest fuels reduction, thinning, planting and disposing of dying trees.

The forests of the Sierra Nevada now contain severely burned patches totaling hundreds of thousands of acres. In many of these areas, where all seed-bearing trees have been killed, trees may not regenerate naturally. Replanting of post-fire areas traditionally has been dense, with over 400 seedlings planted per acre and thinning conducted within the first 10 years. This high-density planting helps trees outcompete shrubs. However, public forest managers often no longer have the capacity to conduct thinning or weed control, leaving untreated, fire-prone stands that are a risk to neighboring forests. Some post-fire areas, such as those on steep, south-facing slopes, may be so fire-prone that reforestation efforts would be wasted; indeed, they probably would not support trees at all (only shrubs) if not for long-term fire suppression.

Moving forward, post-fire restoration should incorporate four key approaches: planning for wildfire and prescribed fire, promoting a diverse forest landscape, anticipating climate change and investing in ongoing experimentation and monitoring.

Plan for wildfire and prescribed fire. Restoration plans should incorporate a fire hazard analysis to help identify restoration priorities and locations. For example, areas where topography and prevailing winds would lead wildfires into communities should be prioritized for removal of dead trees to reduce fuels and the risk from future fires. New plantations should be minimized in areas with the highest fire hazard, such as inner canyon walls with steep slopes; these areas may be better suited to remain in shrub cover to benefit wildlife species that prefer an open, shrub-dominated habitat. Recently burned areas most conducive to prescribed fire should be identified and a plan made for reburning them as fuels accumulate,

\section{The forests of the Sierra Nevada now}

\section{contain severely burned patches}

\section{totaling hundreds of thousands \\ of acres.}


probably within 10 to 15 years in the lower and middle elevations of the Sierra Nevada. Where possible, new plantations should be designed to allow prescribed fire as a management practice, by spacing trees appropriately and incorporating fuel breaks.

Promote diverse forest landscapes. Post-fire restoration plans should also incorporate heterogeneity on the landscape. Recent controversies over post-fire salvage logging after large fires have focused on how many standing dead trees, or snags, to retain for wildlife habitat. Although some advocate for leaving all dead trees alone, very large fires may actually leave more areas of shrubs and standing dead trees than desirable. Instead these landscapes are now lacking in areas of young and old living trees. In these cases, management actions could focus on dead tree removal (to remove future fuels), replanting where future fire risk is lowest and fuel reduction treatments in any stands of old trees within the burns or in nearby forests. The result of this combination of actions would be a mosaic of areas with a variety of ecosystem characteristics, and wildlife habitats, and a reduction in future fire risk.

Anticipate climate change. Restoration projects should start with a climate vulnerability assessment to identify areas where warming will cause the most effects. In areas where the most change is projected, such as lower-elevation south-facing slopes, experiments should be conducted to evaluate planting arrangements, species and seed source and management strategies. Areas that have experienced low-severity fire can be designated as climate refugia, providing bases from which current tree species can migrate to new locations as the climate changes.

Invest in experimentation and monitoring. Learning from post-fire restoration requires that managers explicitly consider these actions as experiments. The history of fire suppression illustrates the need to consider any management as an endeavor that must be reevaluated as social and ecological conditions change. Forest managers and researchers should work together to develop experimental approaches, document successes and failures and share learning around restoration outcomes. The approaches and questions addressed must be shared with stakeholders, including communities in fire-prone areas, so that public opinion can influence and evolve with our understanding of effective post-fire restoration techniques.

\section{The way forward}

It is often said that our government and military are busy refighting the last war instead of fighting the current one, that our definitions of the problems we face and our strategies for combatting them are no longer relevant under current conditions. We have developed a sophisticated fighting force to suppress wildfire at all costs - even though we can no longer

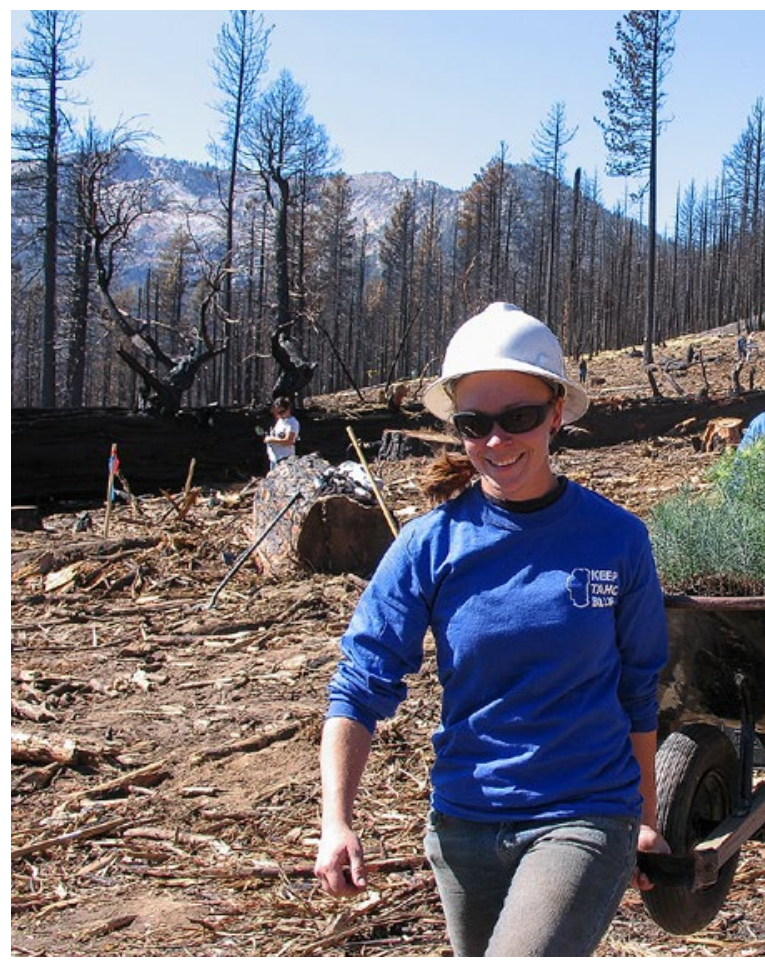

succeed at suppression, and suppression often makes the impacts of future fires more severe. Fire and forest management strategies developed 100 years ago may have made sense at the time, but after 50 years it was obvious, at least to some, that the fire exclusion strategy was at best ineffective and at worst a tragedy in the making (the National Park Service abandoned total fire suppression at about that time). Now, immediate changes in policy are needed from the rest of our state and federal forest and fire agencies.

Moving forward to change the failed policies of the past will be difficult, especially as the prolonged drought of the last few years has made forests more flammable. Yet, there is an opportunity in both burned and unburned areas to test a new approach to forest management. Burned areas in the Sierra Nevada provide forest managers with a laboratory for experimentation and a chance to create forests that can better adapt to the fire and climate conditions of this century and the next. $\mathrm{CA}$

\footnotetext{
References

Knapp EE. 2015. Long-term dead wood changes in a Sierra Nevada mixed conifer forest: Habitat and fire hazard implications. Forest Ecol Manag 339:87-95

Mclntyre PJ, Thorne JH, Dolanc CR, et al. 2015. Twentieth-century shifts in forest structure in California: Denser forests, smaller trees, and increased dominance of oaks. P Natl Acad Sci USA 112:1458-63. North M, Brough A, Long J, et al. 2015. Constraints on mechanized treatment significantly limit mechanical fuels reduction extent in the Sierra Nevada. J Forest 113:40-8.

Ogle CE. 1920. Light burning. The Timberman 21:106-8.
}

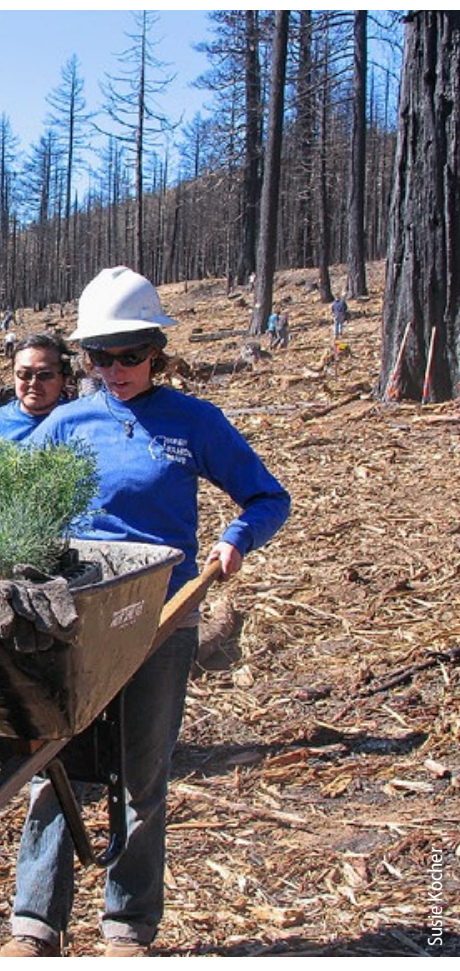

Tahoe Conservancy and League staff carry Jeffrey pine and incense cedar seedlings for planting about 30 acres in the Angora burn area. 